\title{
The Influence of Ceramic Coating on Fatigue Crack Growth Behaviour of X17CrNi15-2 Stainless Steel
}

\author{
Ran Li' ${ }^{1}$, Wenshu Wei ${ }^{1}$, Shoubin Li $^{2}$, Rui Zhao ${ }^{3}$, Hao Liu', Jiankai Zhang1, Jian Ye ${ }^{3}$, Huigang Wu',

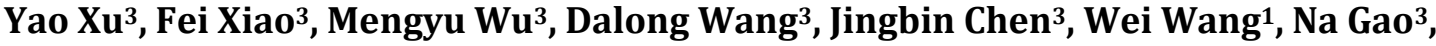 \\ Rongming Chen ${ }^{3}$
}

${ }^{1}$ Intelligent Control Technology Branch, China Coal Research Institute, Beijing, China

${ }^{2}$ Big-Data Research Branch, China Coal Research Institute, Beijing, China

${ }^{3}$ Beijing Tiandi-Marco Electro-Hydraulic Control System Company Ltd., China Coal Technology and Engineering Group, Beijing, China

Email: ranli03@163.com

How to cite this paper: Li, R., Wei, W.S., Li, S.B., Zhao, R., Liu, H., Zhang, J.K., Ye, J., Wu, H.G., Xu, Y., Xiao, F., Wu, M.Y., Wang, D.L., Chen, J.B., Wang, W., Gao, N. and Chen, R.M. (2020) The Influence of Ceramic Coating on Fatigue Crack Growth Behaviour of X17CrNi15-2 Stainless Steel. Engineering, 12, 140-149.

https://doi.org/10.4236/eng.2020.122012

Received: January 2, 2020

Accepted: February 25, 2020

Published: February 28, 2020

Copyright $\odot 2020$ by author(s) and Scientific Research Publishing Inc. This work is licensed under the Creative Commons Attribution International License (CC BY 4.0).

http://creativecommons.org/licenses/by/4.0/

\begin{abstract}
Fatigue crack growth tests were carried out on the SEN B3 precracked specimens, with dimensions in accordance with ISO 12108 requirements. The specimens were made of martensitic stainless steel, X17CrNi15-2, and some of them were modified by the ceramic coating deposition surface treatment. The effects of ceramic coating, on the fatigue crack growth behaviour of hollow shaft specimens, were experimentally investigated. Fatigue crack growth rates, $\mathrm{d} a / \mathrm{d} N$, were characterised, using the power law relationship between $\mathrm{da} / \mathrm{dN}$ (in $\mathrm{mm} /$ cycle) and the stress intensity factor range, $\Delta K$ (in $\left.\mathrm{MPa} \cdot \mathrm{m}^{0.5}\right)$. The two constants of the correlation are $7.9768 \times 10^{-9}$ and 2.8107 for the parent material, and those for the coated material are $2.4391 \times 10^{-9}$ and 3.1990 , respectively. Microstructural analyses were carried out on the tested specimens, which shows that the maximum hardness of the ceramic coating is higher than that of substrate by a factor of $\sim 3.2$. The dimple fracture dominates the final fracture mechanism for the parent material, and the combination of fatigue, ductile fracture and cleavage dominates the final fracture mechanism for the coated material, based on the SEM analyses. EDS tests' results reveal that the parent material specimen shows higher levels of $\mathrm{C}$ at matrix regions along with $\mathrm{Fe}$ - and $\mathrm{O}$-rich regions, compared with the coated material specimen.
\end{abstract}

\section{Keywords}

Fatigue Crack Growth, SEN B3 Precracked Specimen, X17CrNi15-2, Ceramic Coating Deposition Surface Treatment, Corrosion Resistance 


\section{Introduction}

Liquid ends in, for example, reciprocating pumps, etc, often undergo cyclic loading, during their normal service operation. Potential failures of the liquid ends are often associated with the extension of cracks and/or crack-like flaws which may exist within these components. It is therefore critical to investigate the crack propagation due to fatigue. The particles of sediments in the liquids, or cavitation, often lead to the initial cracks. In order to enhance the resistance to wear and cavitation in the liquid ends, the surface modification methods, such as chemical heat treatment (carburizing, nitriding, metalizing, etc.), surface coating technology, physical vapor deposition (PVD), and chemical vapor deposition (CVD) are widely used.

A number of experimental studies have focused on clarifying the effect of the different surface modification methods on the fatigue properties of materials. Malakondaiah and Nicholas [1] found that fatigue crack growth rates for the Ti-24AI-11Nb specimens are reduced by up to three orders of magnitude after applying laser glazing surface treatment at a given stress intensity. Yerokhin et al. [2] reported that the plasma electrolytic oxidation coating with two thicknesses of $\sim 7 \mu \mathrm{m}$ and $\sim 15 \mu \mathrm{m}$ reduced the fatigue lives of magnesium alloy specimens by about $10 \%$. Lonyuk et al. [3] have found that a $60 \mu \mathrm{m}$ hard anodic oxide coating led to a reduction in the fatigue strength of 7475-T6 alloy. Golden et al. [4] have used the diamond-like carbon coating technology to improve the fretting fatigue life of Ti-6Al-4V. Hatamleh et al. [5] studied the weakening influence of laser peening on the fatigue crack growth behaviour of friction stir welded aluminium alloy 7075-T7351 sheets.

The ceramic coating deposition surface treatment [6] is a physical heat treatment method, where a material is immersed in a ceramsite solution containing $\mathrm{TiO}_{3}, \mathrm{Na}_{2} \mathrm{~B}_{4} \mathrm{O}_{2}$ and other components at $150^{\circ} \mathrm{C}$ and cured at room temperature. The technique is suitable for the surface treatment of complicated internal structures resulting in the enhanced resistance to wear and cavitation. In this paper, we applied ceramic coating deposition surface treatment to X17CrNi15-2, a martensitic stainless steel that is widely used for making liquid ends of reciprocating pumps. The fatigue cracking mechanism and some material properties of the test specimens are determined from various material characterizing methods.

\section{Fatigue Crack Growth Tests}

\subsection{Test Material and Specimens}

A martensitic stainless steel, X17CrNi15-2, was used in this study, which is a favorable material in liquid-end manifold of reciprocating pump due to its excellent hardness, tensile strength and corrosion-resistance [7]. The material properties of the X17CrNi15-2 are shown in Table 1.

The tested specimens used are standard SEN B3 precracked specimens, with dimensions in accordance with ISO 12108-2018 requirements [8]. These specimens were fabricated from a forged block with dimensions of $400 \times 500 \times 800 \mathrm{~mm}$, 
Table 1. Chemical compositions of X17CrNi15-2 (wt\%).

\begin{tabular}{cccccccccccc}
\hline Material & $\mathrm{Si}$ & $\mathrm{V}$ & $\mathrm{Cr}$ & $\mathrm{Mn}$ & $\mathrm{Co}$ & $\mathrm{Ni}$ & $\mathrm{Cu}$ & $\mathrm{Zn}$ & $\mathrm{Mo}$ & $\mathrm{Sn}$ & $\mathrm{S}$ \\
\hline X17CrNi15-2 & 0.769 & 0.106 & 16.29 & 0.409 & 0.215 & 1.97 & 0.259 & 0.017 & 0.181 & 0.015 & 0.099 \\
\hline
\end{tabular}

of which the hardness, i.e. 45HRC, is obtained by head treatment. A pre-crack of $5.5 \mathrm{~mm}$ in length was machined using the electric discharge machining method [9] [10]. All of the SEN B3 specimens have the same initial crack length $a_{0}$ $=11.85 \mathrm{~mm}$, the thickness $B=40 \mathrm{~mm}$, and the width $W=80 \mathrm{~mm}$. The configuration of the SEN B3 precracked specimen is shown in Figure 1.

The ceramic coating deposition surface treatment [6] was carried out, where some of the test specimens were immersed in a ceramsite solution containing $\mathrm{TiO}_{3}, \mathrm{Na}_{2} \mathrm{~B}_{4} \mathrm{O}_{2}$ and other materials at $150^{\circ} \mathrm{C}$ and cured at room temperature. This technique can enhance wear resistance of the specimen surfaces, without the decrease in corrosion resistance of the stainless steel.

\subsection{Test Procedure}

The test rig, used for the testing of the SEN B3 specimens, is INSTRON1343 electro-hydraulic servo universal testing machine, as shown in Figure 2. Besides the framework and the base, the test rig consists of two servo-hydraulic actuators to provide axial load, which is suitable for the tension-tension testing of the specimens. The automated control of the test rig was achieved by a digital controller on a computer. In-phase sinusoidal load profiles, with a frequency of $50 \mathrm{~Hz}$, and an axial load with a stress ratio of 0.1 , were applied to the fatigue crack growth tests. A crack-opening-displacement (COD) technique was used to measure crack lengths in SEN B3 specimens for the determination of fatigue crack growth rates. A total of six tests were carried out: three tests for parent material specimens and three tests for the ceramic coated specimens. A constant maximum axial load, i.e. $60 \mathrm{kN}$, was applied in all cases.

\section{3. $\Delta K$ Calculation}

According to ISO 12108-2018 [8], the stress-intensity factor $K$, of SEN B3 specimens, can be calculated using the applied forces and the corresponding crack lengths obtained from the fatigue crack growth tests, using Equation (1):

$$
K=\frac{F}{B W^{1 / 2}} g\left(\frac{a}{W}\right)
$$

where $F$ is the applied force, $B$ is the specimen thickness, $W$ is the specimen thickness measured from the reference plane to the specimen edge, $g(a / W)$ is stress-intensity factor geometry function, which can be obtained using Equation (2):

$$
g\left(\frac{a}{W}\right)=\frac{6 \alpha^{1 / 2}}{(1+2 \alpha)(1-\alpha)^{3 / 2}}\left[1.99-\alpha(1-\alpha)\left(2.15-3.93 \alpha+2.7 \alpha^{2}\right)\right]
$$

where $\alpha=a / W . a$ is the crack length and $W$ is the specimen width, as shown in Figure 1 . 


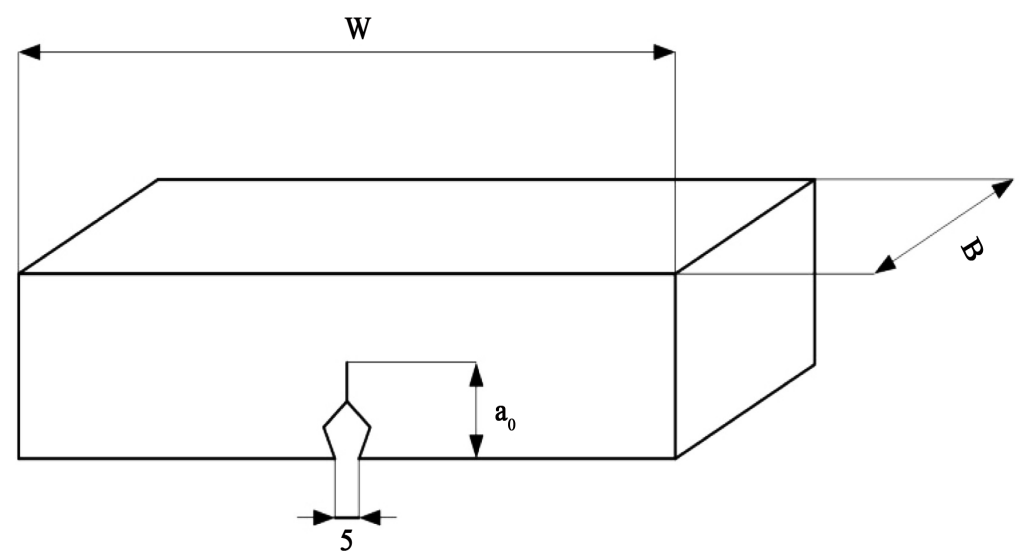

Figure 1. Configuration of the SEN B3 specimen.

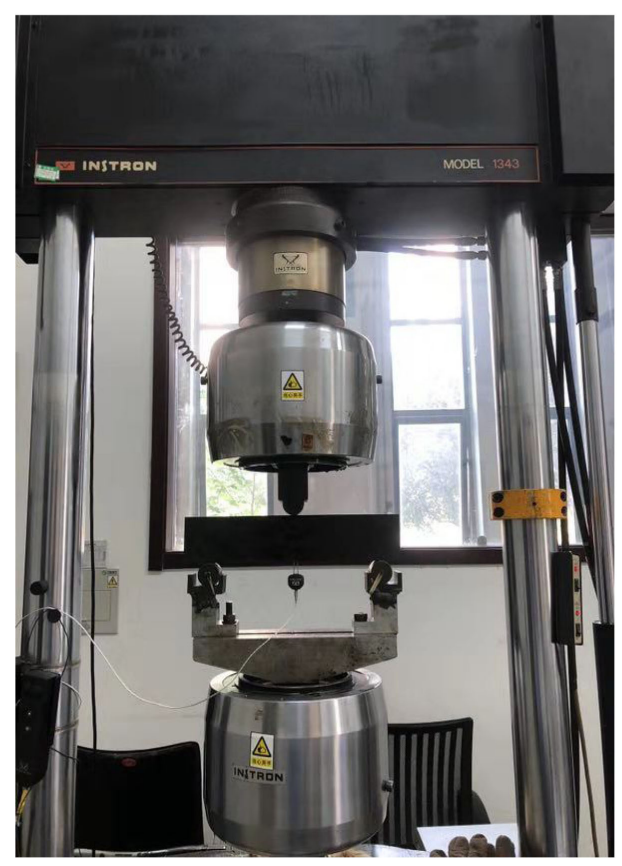

Figure 2. Apparatus of fatigue crack growth tests.

Hence, the stress-intensity factor range $\Delta K$, can be calculated by Equation (3):

$$
\Delta K=K_{\max }-K_{\min }
$$

where $K_{\max }$ and $K_{\min }$ are the maximum and minimum stress intensity factors, corresponding to maximum and minimum applied forces, respectively.

\section{Experimental Results}

\subsection{Crack Growth Data}

Figure 3 shows the change in crack length along the test cycles for the parent and coated material specimens. There were no significant scatters observed through the fatigue life, $N_{f}$ for coated material specimens as compared to the parent material specimens. 


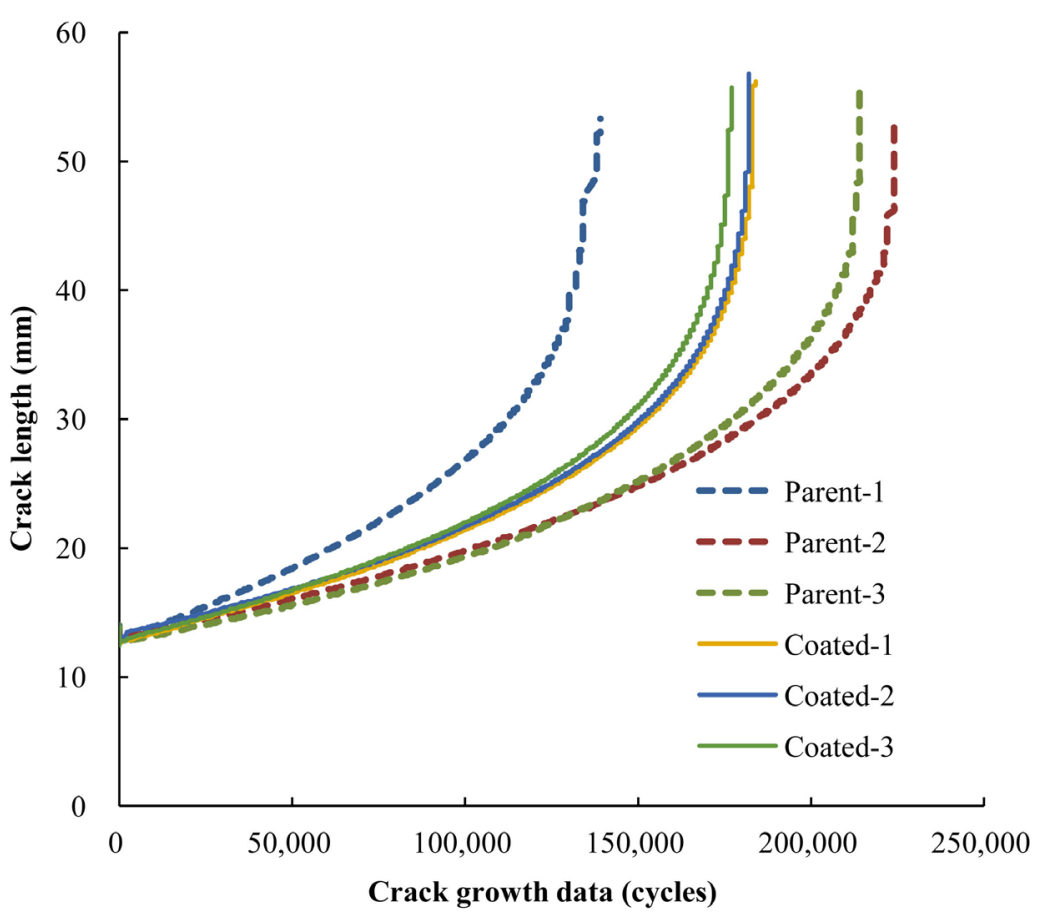

Figure 3. Fatigue crack growth data for both parent material and coated material specimens.

The fatigue life, $N_{f}$ varies from 139,000 to 224,000 for the parent material specimens which is about 181,000 for the coated material specimens. The test matrix for the SEN B3 specimens is shown in Table 2.

The fracture surfaces for a selection of the two types of specimens are shown in Figure 4. It is found that no crack tunneling occurs for both the parent material specimen and the coated material specimens.

\subsection{Pairs' Law Parameters for Parent and Coated Materials}

The experimental data were processed based on the standard of ISO 12108-2018 [8] and invalid data were excluded. The crack growth rates were obtained by the use of the seven-point incrementing polynomial method. The crack growth rate, $\mathrm{d} a / \mathrm{d} N$ (in $\mathrm{mm} / \mathrm{cycle}$ ) are characterized by the Paris law [11], a well-known power law equation. As a result, the crack growth rate, $\mathrm{d} a / \mathrm{d} N$, can be correlated with the stress intensity factor range, $\Delta K$, which is shown in Equations (4) and (5), for parent material and coated material specimens, respectively. The experimental data can be well fitted in the characteristic equations, as shown in Figure 5.

$$
\frac{\mathrm{d} a}{\mathrm{~d} N}=7.9768 \times 10^{-9}(\Delta K)^{2.8107}
$$

for the parent material SEN B3 specimens and

$$
\frac{\mathrm{d} a}{\mathrm{~d} N}=2.4391 \times 10^{-9}(\Delta K)^{3.1990}
$$

for the coated material SEN B3 specimens. 


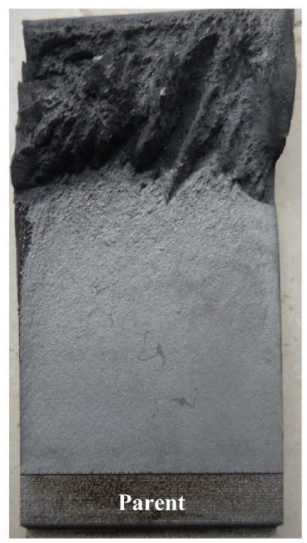

(a)

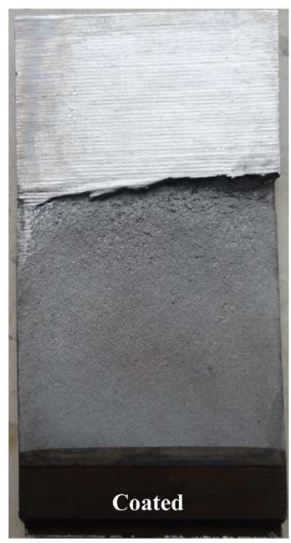

(b)

Figure 4. The fracture surfaces for a selection of the specimens.

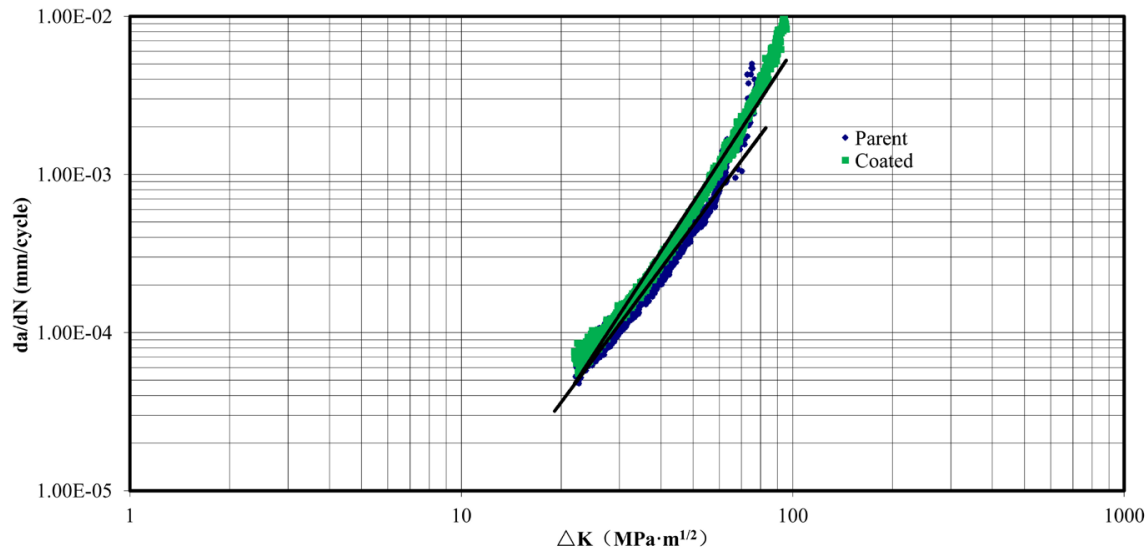

Figure 5. da/d $N$ against $\Delta K$ for the parent material specimens and coated material specimens.

Table 2. Test matrix for the SEN B3 specimens.

\begin{tabular}{cccc}
\hline Specimens & Maximum load $(\mathbf{k N})$ & Stress ratio, $\mathbf{R}$ & Fatigue life, $\boldsymbol{N}_{\boldsymbol{f}}$ (cycles) \\
\hline Parent-1 & 60 & 0.1 & 139000 \\
Parent-2 & 60 & 0.1 & 224000 \\
Parent-3 & 60 & 0.1 & 214000 \\
Coated-1 & 60 & 0.1 & 184000 \\
Coated-2 & 60 & 0.1 & 182000 \\
Coated-3 & 60 & 0.1 & 177000 \\
\hline
\end{tabular}

\section{Microstructural Analyses of the Tested Specimens}

\subsection{Microstructure Analysis and Hardness Profiles}

The microstructure of a typical ceramic-coated layer was observed on the cross-section area of the tested specimen, which is shown in Figure 6. It can be seen that the cross-section consists of three distinct regions, i.e. the ceramic-coated region, the transition region and substrate region. The thickness of the ceramic-coated layer is about $200 \mu \mathrm{m}$. Figure 7 presents the hardness profile 


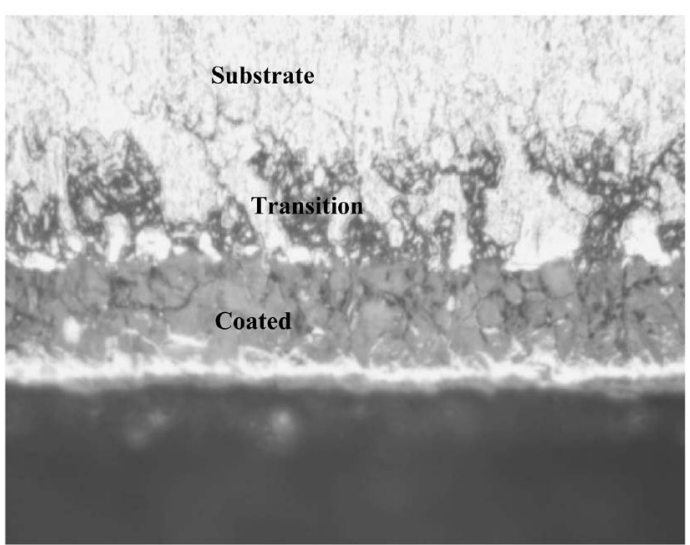

Figure 6. The cross-section microstructure of a typical ceramic-coated layer of the tested specimen.

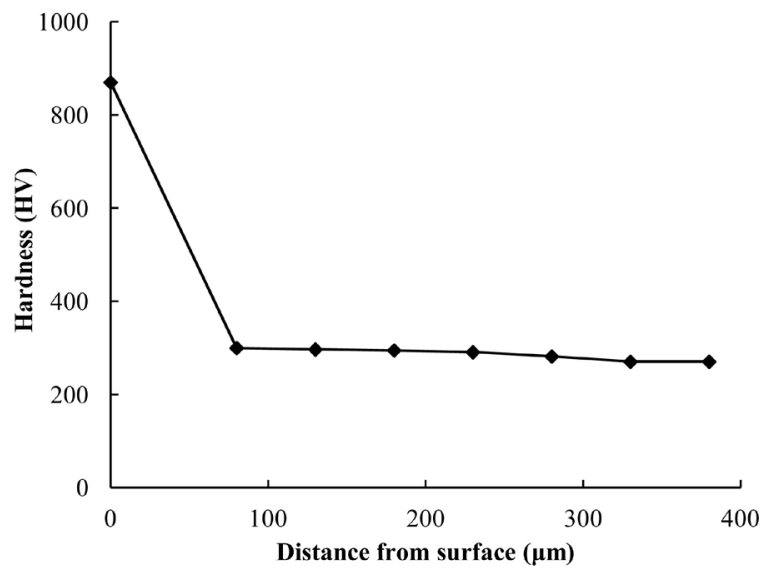

Figure 7. The hardness distribution along the ceramic-coated specimen.

which is carried out at the top of the coating surface and across the substrate region. The maximum hardness value of the ceramic-coated layer is about $870 \mathrm{HV}$ while the hardness for the X17CrNi15-2 substrate is only $270 \mathrm{HV}$. The hardness profile shows that the ceramic-coated surface results in an increase in hardness.

\subsection{SEM and EDS Analyses of Specimens}

In order to determine the mechanisms and chemical compositions associated with each phase of the fatigue damage process, SEM and EDS analyses were carried out on both parent material and coated material specimens. Figure 8 shows the SEM images of fatigue fracture surfaces of the parent material specimen at different stages, namely crack initiation, crack propagation and final fracture. It is found that the fatigue behaviour dominates the crack initiation and propagation stages for the parent material specimen. The fracture mechanism of the final fracture stage is dimple fracture, as shown in Figure 8(c). The SEM images of fatigue fracture surfaces of the parent material specimen at different stages as shown in Figure 9. Similar results are obtained for the coated specimen during the crack initiation and propagation stages. However, the final fracture for the 
coated specimen is caused by the combination of fatigue, ductile fracture and cleavage, as shown in Figure 9(c). Figure 10 shows the EDS analyses of the parent material and coated material specimens at the final fracture stage. It is found that the parent material specimen shows higher levels of $\mathrm{C}$ at matrix regions along with $\mathrm{Fe}$ - and $\mathrm{O}$-rich regions, compared with the coated material specimen.

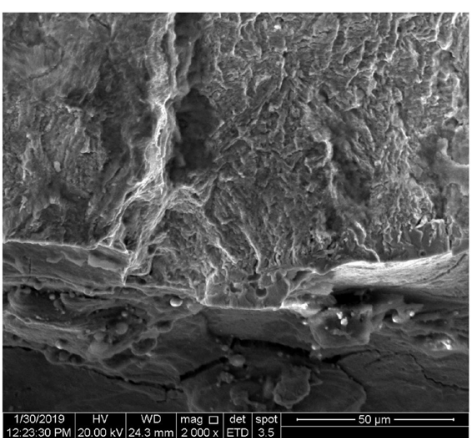

(a)

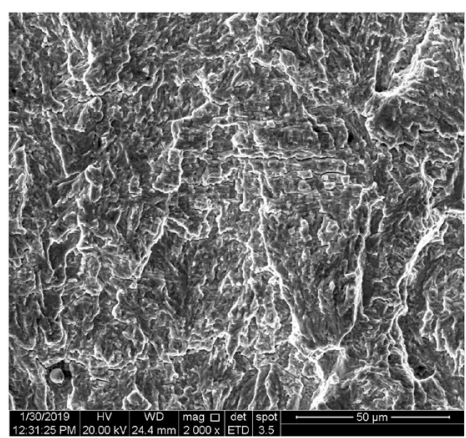

(b)

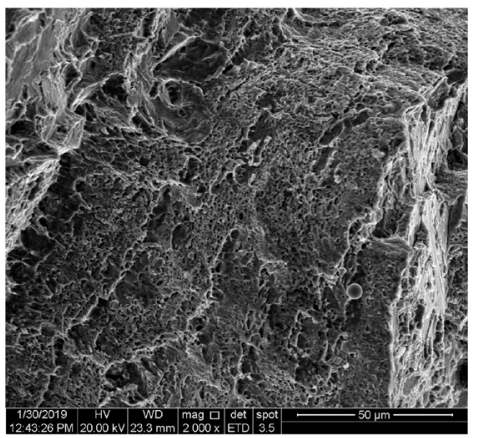

(c)

Figure 8. SEM features of fracture surfaces of the parent material specimen for (a) crack initiation; (b) crack propagation; (c) final fracture.

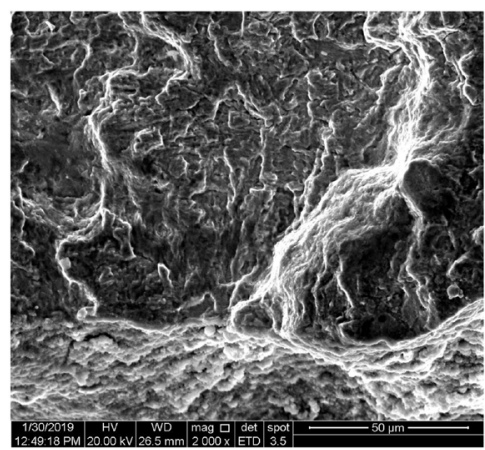

(a)

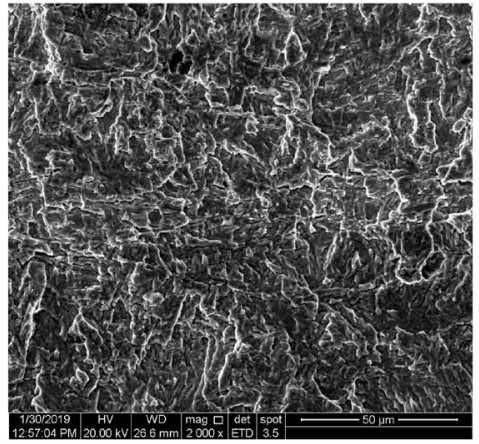

(b)

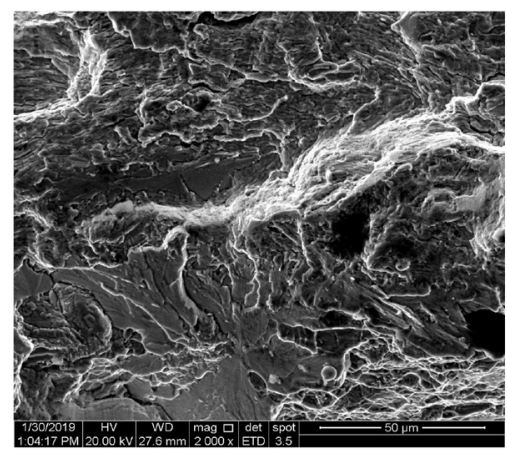

(c)

Figure 9. SEM features of fracture surfaces of the coated material specimen for (a) crack initiation; (b) crack propagation; (c) final fracture.

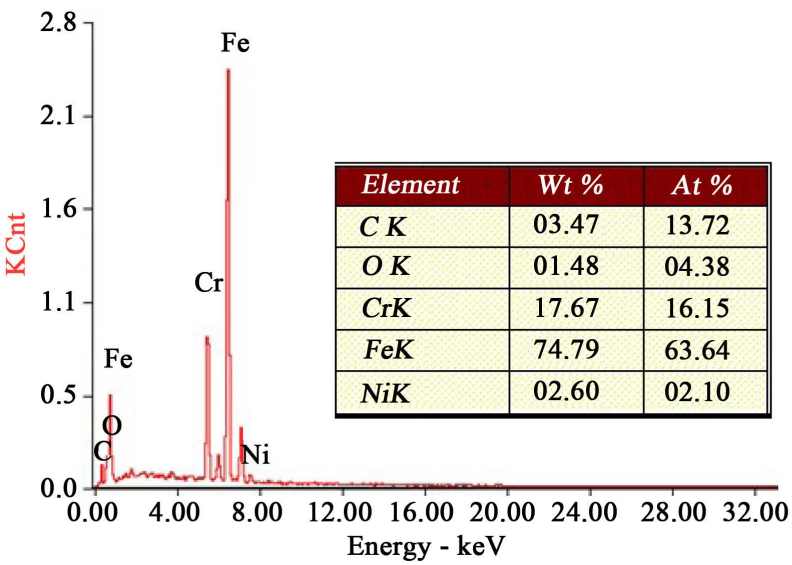

(a)

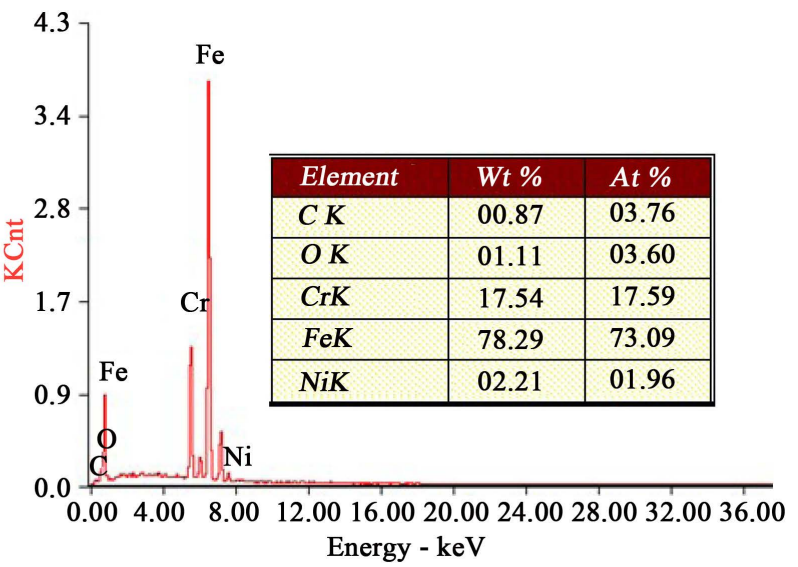

(b)

Figure 10. EDS analyses of (a) the parent material specimen and (b) the coated material specimen. 


\section{Discussion and Concluding Remarks}

The influence of ceramic coating on fatigue crack growth behaviour of X17CrNi15-2 stainless steel was investigated. The SEN B3 specimens with and without surface treatment were prepared and used in fatigue crack growth tests. The test results show that there was no significant scatter in the fatigue life of the specimens. The concluding remarks are shown as follows:

- The Paris law relationships for the parent material and coated materials are also obtained from experiments, which reveals that fatigue crack growth rates of the coated specimens are higher than those of the parent material specimens for the same stress intensity factor range, $\Delta K$.

- Furthermore, the effects of ceramic coating are also determined through material properties and microstructural analysis. The ceramic coating exhibits a maximum hardness value of $870 \mathrm{HV}$, which is higher than that of the parent material by a factor of $\sim 3.2$. The increase in the hardness will significantly enhance the resistance to the wear and cavitation for X17CrNi15-2 stainless steel. The SEM and EDS analyses confirm the differences in mechanism and chemical compositions for the final fracture of the parent material and coated material specimens.

- Future research work related to this topic can move towards the comparison among different surface modification methods applied to X17CrNi15-2 stainless steel.

\section{Acknowledgements}

This research was supported by the National Key Research and Development Program of China (2017YFC0804300, 2017YFC0804304), NDRC Project (NDRC Investment (2015) No.1780) and CCTEG Project (2018-TD-ZD015, 2018MS027) funding.

\section{Conflicts of Interest}

The authors declare no conflicts of interest regarding the publication of this paper.

\section{References}

[1] Malakondaiah, G. and Nicholas, T. (1994) The Influence of Laser Glazing on Fatigue Crack Growth in Ti-24AI-11Nb. Metallurgical \& Materials Transactions A, 25, 183-192. https://doi.org/10.1007/BF02646686

[2] Yerokhin, A.L., Shatrov, A., Samsonov, V., et al. (2004) Fatigue Properties of Keronite Coatings on a Magnesium Alloy. Surface \& Coatings Technology, 182, 78-84. https://doi.org/10.1016/S0257-8972(03)00877-6

[3] Lonyuk, B., Apachitei, I. and Duszczyk, J. (2007) The Effect of Oxide Coatings on Fatigue Properties of 7475-T6 Aluminum Alloy. Surface \& Coatings Technology, 201, 8688-8694. https://doi.org/10.1016/j.surfcoat.2006.02.002

[4] Golden, P.J. and Shepard, M.J. (2007) Life Prediction of Fretting Fatigue with Advanced Surface Treatments. Materials Science and Engineering. A, 468, 15-22. 
https://doi.org/10.1016/j.msea.2006.10.168

[5] Hatamleh, O., Lyons, J. and Forman, R. (2007) Laser and Shot Peening Effects on Fatigue Crack Growth in Friction Stir Welded 7075-T7351 Aluminum Alloy joints. International Journal of Fatigue, 29, 421-434.

https://doi.org/10.1016/j.ijfatigue.2006.05.007

[6] Zhang, Y.F. (2015) Preparation of a Tough Special Ceramic Composite Diffusion Layer, CN 103243323 B[P].

[7] Li, R., Wei, W.S., Liu, H., et al. (2019) Simulation Study on LIQUID-End of High-Pressure and Large-Flow-Rate Reciprocating Pump. Proceedings of IEEE the 8 th International Conference on Fluid Power and Mechatronics, Wuhan, China, 10-13 April 2019, In Press.

[8] (2018) ISO 12108-2018[S]. Metallic Materials-Fatigue Testing-Fatigue Crack Growth Method, International Organization Standardization.

[9] Hyde, T.H., Li, R., Sun, W., et al. (2010) A Simplified Method for Creep Crack Growth Prediction of a P91 Weld at $650^{\circ} \mathrm{C}$. Proceedings of the Institution of Mechanical Engineers, Part L: Journal of Materials. Design and Applications, 224, 208-219. https://doi.org/10.1243/14644207JMDA330

[10] Li, R., Hyde, T.H., Sun, W., et al. (2014) Fatigue Crack Growth Testing of the Super CMV Hollow Shafts under Combined Torsional and Axial Loading. Engineering Failure Analysis, 36, 173-185. https://doi.org/10.1016/j.engfailanal.2013.09.021

[11] Paris, P.C., Gomez, M.P. and Anderson, W.E. (1960) A Rational Analytic Theory in Engineering. The Trend in Engineering, 13, 9. 